\title{
BMJ Open Low health literacy and cancer screening among Chinese Americans in California: a cross-sectional analysis
}

\author{
Tetine L Sentell, ${ }^{1}$ Janice Y Tsoh, ${ }^{2}$ Terry Davis, ${ }^{3}$ James Davis, ${ }^{4}$ Kathryn L Braun ${ }^{5}$
}

To cite: Sentell TL, Tsoh JY, Davis T, et al. Low health literacy and cancer screening among Chinese Americans in California: a crosssectional analysis. BMJ Open 2015;5:e006104.

doi:10.1136/bmjopen-2014006104

- Prepublication history for this paper is available online. To view these files please visit the journal online (http://dx.doi.org/10.1136/ bmjopen-2014-006104).

Received 15 July 2014 Revised 3 October 2014 Accepted 6 November 2014

\section{(a) CrossMark}

${ }^{1}$ Office of Public Health Studies, University of Hawaii, Honolulu, Hawaii, USA 2Department of Psychiatry, University of California, San Francisco,

San Francisco, California, USA

${ }^{3}$ Louisiana State University Health Sciences Center, Shreveport, Louisiana, USA ${ }^{4}$ Biostatistics Core, John A. Burns School of Medicine, University of Hawaii, Honolulu, Hawaii, USA ${ }^{5}$ Office of Public Health Studies, University of Hawaii and 'Imi Hale Native Hawaiian Cancer Network, Honolulu, Hawaii, USA

Correspondence to Dr Tetine L Sentell; tsentell@hawaii.edu

\section{ABSTRACT}

Objectives: Cancer is the leading cause of death among Asian Americans. Chinese Americans comprise the largest Asian American ethnic group. Low health literacy (LHL) is associated with lower cancer screening rates, but this association has not been studied in Chinese Americans. We examined the relationship between LHL and meeting US Preventive Service Task Force (USPSTF) guidelines for cervical, colorectal and breast cancer screening among Chinese Americans.

Design: Observational study of Chinese respondents in the 2007 California Health Interview Survey, a population-based survey. Interview languages included English, Cantonese and Mandarin.

Setting: California, USA

Participants: Chinese respondents in age/gender groupings appropriate for USPSTF cancer screening guidelines (cervical: women ages 21-65, $n=632$; colorectal: men or women ages $50-75, n=488$; and breast. women ages $50-74, n=326)$.

Outcomes: Relationships were tested using multivariable logistic regression models controlling for healthcare access and demographic factors, including limited English proficiency (LEP). The combined effects of having both LHL and LEP were specifically examined. LHL was measured by 2-items on perceived ease-of-use of written medical materials. All study variables were self-reported.

Results: Cancer screening percentages among Chinese Americans were $77.8 \%$ for cervical, $50.9 \%$ for colorectal ( $47.9 \%$ for women and $54.2 \%$ for men), and $85.5 \%$ for breast. LHL was associated with lower odds of meeting breast cancer screening guidelines (OR $0.41 ; 95 \% \mathrm{Cl} 0.20$ to 0.82 ). Respondents with both LHL and LEP were significantly less likely to have upto-date colorectal (OR $0.49 ; 95 \% \mathrm{Cl} 0.25$ to 0.97 ) and breast cancer screening (OR $0.21 ; 95 \% \mathrm{Cl} 0.08$ to 0.54 ) than those with neither health communication barrier. In all multivariable models, having seen a physician in the past year was a significant predictor of an up-to-date screening.

Conclusions: In Chinese Americans, LHL and LEP were negatively associated with up-to-date breast and colorectal cancer screening, independent of a recent physician visit. Efforts to promote cancer screening among Chinese Americans should consider and address LHL, LEP and physician access barriers.

\section{Strengths and limitations of this study}

- This study provides new information about the important, distinct roles of low health literacy and limited English proficiency in cancer screening guideline adherence among Chinese Americans using a population-based sample.

- We found that low health literacy was negatively associated with up-to-date breast cancer screening among Chinese Americans.

- We also found that the combination of low health literacy and limited English proficiency was negatively associated with up-to-date colorectal and breast cancer screening among Chinese Americans.

- This study took place in California and used selfreported health literacy measures. Future work should consider the generalisability of these findings across other communities and other health literacy domains.

- Efforts to promote screening in Chinese American communities should consider the health communication barriers of low health literacy and limited English proficiency separately and in combination to improve screening rates in these populations.

\section{INTRODUCTION}

Cancer is the leading cause of death among Asian Americans. ${ }^{1}$ Chinese Americans comprise the largest Asian ethnic group in the $\mathrm{USA}^{2}$ and have particularly low cancer screening rates. ${ }^{3}{ }^{4}$ For instance, Chinese American women are less likely than many Asian American and Pacific Islander women to report having a recent Pap smear or mammogram. ${ }^{3}{ }^{4}$ Underuse of colon cancer screening is also seen among Chinese American men and women. ${ }^{5}$ Gaining a better understanding of the predictors of cancer screening among distinct Asian American populations, such as Chinese Americans, is important for targeted cancer control interventions. ${ }^{67}$

Health literacy, 'the degree to which individuals have the capacity to obtain, process, and understand basic health information and 
services for appropriate health decisions, ${ }^{8}$ is an established correlate to cancer screening. ${ }^{9}{ }^{10}$ Low health literacy is associated with limited knowledge about cancer screening, lack of desire for screening and poorer access to care. ${ }^{11-19}$ Limited research has focused on low health literacy in cancer screening among Chinese Americans specifically.

An additional issue to consider for cancer screening in Chinese Americans is limited English proficiency (LEP). Over half (58\%) of Chinese Americans have LEP, a major health communication barrier. ${ }^{20}$ Previous studies have found that LEP is associated with lower rates of cancer screening generally and specifically in Chinese Americans. ${ }^{21-23}$ For instance, 57\% of Chinese American women with LEP reported having a Pap test compared to $76 \%$ who were English proficient. ${ }^{23} \mathrm{~A}$ recent analysis of a population-based database in California found that Asian Americans with both LEP and low health literacy, or with LEP-only, were significantly less likely to be screened compared to those with neither limited literacy nor LEP. ${ }^{19}$

This study had two primary aims. The first was to examine the relationship between low health literacy and meeting the US Preventive Service Task Force (USPSTF) guidelines for cervical, colorectal and breast cancer screening among Chinese Americans in California. ${ }^{24-26}$ These three cancers share four traitsthey represent significant public health problems, have strong methods for early detection, have evidence that screening is useful, and show disparities among Asian American groups. ${ }^{3-8}$ The second aim was to quantify the combined burdens of low health literacy and limited English proficiency on meeting the guidelines. Evidence suggests that the combination of these two health communication barriers may indicate a particular vulnerability to not receiving recommended cancer screening. ${ }^{19}$

\section{METHODS}

\section{Sample}

The 2007 California Health Interview Survey (CHIS) ${ }^{27}$ was used. The CHIS is a random-digit-dial (RDD) telephone survey administered by UCLA Center for Health Policy Research. It is representative of the noninstitutionalised population of California, which is home to 4 out of every 10 Asian Americans in the USA. ${ }^{28}$ The 2007 CHIS multistage sample design included landline and cellular telephone numbers. ${ }^{29}$ For the landline RDD sample, the state was divided into 44 geographic sampling strata from which residential telephone numbers were selected. Within each household, one adult (18 years and over) respondent was randomly selected. The separate RDD cellular sample was drawn from telephone numbers assigned to cellular service and stratified by area code. ${ }^{29}$ The CHIS interviews in Mandarin and Cantonese, ${ }^{30}$ allowing for participation by Chinese individuals with limited English proficiency. CHIS English proficiency and cancer screening variables have been used extensively in other studies on this subject. ${ }^{31-35}$

\section{Outcomes}

Breast cancer. In the 2007 CHIS, following National Health Interview Survey protocol, ${ }^{36}$ women 30 years and older were asked if they ever had a mammogram. Those who had received one were asked, "How long ago did you have your most recent mammogram?" USPSTF ${ }^{24}$ defines meeting breast cancer screening guidelines as having a mammogram in the past 1-2 years for women aged 50-74. Cervical cancer: women 18+who were not currently pregnant and had never had a hysterectomy were asked if they ever had a Pap smear. If yes, they were asked, "How long ago did you have your most recent Pap smear test?" Following USPSTF ${ }^{25}$ guidelines, meeting cervical cancer screening was defined as a Pap smear in the past 1-3 years for women aged 21-65. Colorectal cancer. compliance with colorectal screening guidelines was obtained for all participants 50 years and older based on a series of cancer screening variables concerning fecal occult blood test (FOBT) in the past year, a flexible sigmoidoscopy or double-contrast barium enema in the past 5 years, or a colonoscopy in the past 10 years, per USPSTF guidelines. ${ }^{26}$ Respondents who reported a colorectal cancer (CRC) test were asked if they completed the test due to a problem. (Approximately 4-8\%, depending on the specific CRC test, did so.) Meeting colorectal cancer screening guidelines was defined as 'yes' for the compliance guideline variable for men and women 50-75 excluding the 4-8\% who took a CRC test due to a problem, as utilisation for diagnostic purposes may be subject to different factors than screening.

\section{Low health literacy}

Health literacy in the 2007 CHIS was assessed by two questions: (1) "When you get written information at a doctor's office, would you say that it is very easy, somewhat easy, somewhat difficult, or very difficult to understand?" and (2) "When you read the instructions on a prescription bottle, would you say that it is very easy, somewhat easy, somewhat difficult, or very difficult to understand?" Respondents could report not getting written information $(<4 \%$ of all respondents) or not using prescription medicine $(<2 \%$ of all respondents). In the full sample, $<1 \%$ of the sample lack a response to either question. Low health literacy was defined as responding that either one of these two tasks were 'somewhat' or 'very difficult' to understand. ${ }^{19} 3738$ These items are similar to validated health literacy self-report measures ${ }^{39}$ that perform well in identifying low health literacy relative to standard instruments and these particular items have been used in a number of previous studies. ${ }^{19} 3738$

\section{Limited English proficiency}

Respondents who spoke any language(s) at home besides English were asked: "Since you speak a language other than English at home, we are interested in your own opinion of how well you speak English. Would you say you speak English very well, well, not well, or not at 
all?" LEP was defined as self-reporting speaking English 'not well' and 'not at all.' This LEP variable is considered a superior measure for language barriers in health, ${ }^{40}$ has strong face validity and is standard in many studies. $^{41} 42$

\section{Low health literacy and LEP combined burdens}

Previous research has found that having both low health literacy and LEP together is associated with notably poor rates of colorectal cancer screening ${ }^{19}$ as well as other health disparities, such as poor health. ${ }^{38}$ Thus, a fourcategory variable was created using low health literacy and LEP combinations, coded 1 =both LEP and low health literacy, 2=only LEP, $3=$ only low health literacy, and $4=$ neither LEP nor low health literacy.

\section{Covariates}

For multivariable models, control variables included: Age (continuous 18-75), sex (male or female, as relevant), education (less than high school, high school graduate, college graduate, more than college), poverty ( $\leq 100 \%$, of poverty vs not), living in a rural area (vs not), current insurance (vs none), being born in the USA (vs elsewhere) and marital status (married vs other). These variables are associated with health literacy, limited English proficiency and/or cancer screening in other studies. ${ }^{43}$ As insurance coverage does not necessarily guarantee healthcare access, we also included the dichotomous item (yes=1 or no=0) for "Visited a doctor in the past 12 months?"i

\section{Language concordance}

Based on previous research, ${ }^{44}$ we also examined the role of patient-provider language concordance in compliance with cancer screening guidelines specifically among those with LEP. The patient-provider language concordance variable had two groups: (1) other-language concordant (patients and providers spoke the same non-English language) or (2) language discordant (patient did not share a language with their provider). ${ }^{19} 45$ For Chinese Americans with LEP, we first considered whether the language concordance variable had a significant relationship with each type of cancer screening in bivariate models. Then, for screening types in which a significant relationship was found for language concordance, language concordance was included in final multivariable models.

\section{Samples}

This study included three samples as different age groups and gender combinations are targeted by a distinct set of screening guidelines. Following the USPSTF

${ }^{\mathrm{i}} \mathrm{We}$ tested other potential control variables, including language of interview (English vs. Cantonese or Mandarin) and years in the US $(<5,5-10,15+$ years $)$ for those born outside the US. However, these were not included in final models because of collinearity with limited English proficiency and birthplace variables. guidelines, ${ }^{24-26}$ the cervical cancer sample included women ages 21-65, the breast cancer sample included women ages 50-74 and the colorectal cancer sample included men or women ages 50-75. All samples excluded individuals with missing health literacy measures and/or missing information regarding the screening outcome of interest. The unweighted sample sizes are as follows: cervical: 632; colorectal: 488; and breast: 326 .

\section{Statistical methods}

The 2007 CHIS public-use data file was used for all analyses. All data were analysed in STATA V.10.0 ${ }^{46}$ using appropriate weighting methods to both correct for the complex sample design and to provide population-level estimates using the CHIS variables provided for this purpose in the public-use data file. ${ }^{47}$ Population-total weighting information was derived using data from the California Department of Finance's 2007 Population Estimates and 2007 Population Projections across 11 demographic, geographic, household composition and socioeconomic factors. ${ }^{47}$

We first report descriptive statistics and cancer screening by low health literacy, compared using $\chi^{2}$ analyses. We then ran multivariable logistic regression models predicting cancer screening for each sample by low health literacy with LEP including control variables (US nativity, age, sex, marital status, insurance, education, living in a rural area, poverty and recent doctor visit). All tests of statistical significance were two sided.

We then ran the same models including the four LEP and low health literacy combination groupings to examine and quantify the combined low health literacy and LEP burdens on cancer screening. Having neither low health literacy nor LEP was the reference group.

\section{RESULTS}

As seen in table $1,85.5 \%$ met breast cancer screening guidelines, $77.8 \%$ met cervical screening guidelines, and $50.9 \%$ met colorectal screening guidelines $(47.9 \%$ for women and $54.2 \%$ for men). Low health literacy was almost $30 \%$ or higher among all samples. LEP was above $40 \%$ in the breast cancer and CRC cancer screening samples, and almost 30\% in the cervical cancer group. Many individuals had both LEP and low health literacy: $29 \%$ in the breast screening sample; $17 \%$ in the cervical sample, and $27 \%$ in the CRC sample. Of interest, $84 \%$ or more of each sample was born outside of the USA, $45-60 \%$ of each sample had a college degree (although perhaps from another country), 12-16\% were living at or under $100 \%$ of the federal poverty level and about 8$15 \%$ were uninsured. Across all samples, a little more than $80 \%$ had visited a doctor in the past year.

As seen in table 2, in adjusted models including low health literacy and LEP separately, a recent physician's visit was highly associated with up-to-date cancer screening in all three samples with an OR greater than 2 in all three models. Independent of a recent physician's visit, 
Table 1 Descriptive data for cancer screening samples data in 2007 CHIS for Chinese respondents

\begin{tabular}{llll}
\hline Samples & Breast cancer screening & Cervical cancer screening & CRC screening \\
\hline Inclusions & Females, age 50-74 & Females, age 21-65 & Females and males, age 50-75 \\
Unweighted N & 326 & 632 & 488 \\
& Per cent & Per cent & Per cent \\
Met screening guidelines & 85.5 & 77.8 & 50.9 \\
LHL & 36.3 & 29.7 & 37.6 \\
LEP & 46.9 & 28.7 & 41.1 \\
LHL and LEP combinations & & & \\
Both LHL and LEP & 29.0 & 17.4 & 27.0 \\
LHL-only & 17.9 & 11.2 & 14.1 \\
LEP-only & 7.2 & 12.3 & 10.6 \\
Neither LHL and LEP & 45.9 & 59.1 & 48.3 \\
Education & 20.7 & & \\
Less than HS & 34.1 & 9.0 & 13.4 \\
High school graduation & 26.5 & 30.1 & 32.8 \\
College graduation & 33.9 & 28.4 \\
More than college degree & 18.9 & 27.0 & 25.5 \\
Age group & & & \\
Young (18-24) & 70.4 & 11.0 & - \\
Middle (25-64) & 29.6 & 87.0 & 67.0 \\
Older (65+) & 1.9 & 33.0 \\
Control variables & 10.0 & 16.5 & \\
Born in USA & 16.1 & 11.7 & 11.0 \\
S100\% Fed poverty level & 2.1 & 4.9 & 14.8 \\
Rural residency & 81.1 & 66.8 & 86.1 \\
Married & 100 & 100 & 52.5 \\
Female & 89.9 & 84.7 & 91.6 \\
Insured & 84.8 & 16.4 & 82.4 \\
Visited doctor in past year & 16.9 & & \\
Language discordant provider & lowhealth literacy; HS, highschool. & \\
LEP, limited English proficiency; LHL, & &
\end{tabular}

Table 2 Logistic models predicting met the US preventive service task force cancer screening guidelines for breast, cervical and colorectal cancer (CRC) by health literacy in 2007 California Health Interview Survey among Chinese respondents

\begin{tabular}{|c|c|c|c|}
\hline & $\begin{array}{l}\text { Breast cancer screening } \\
\text { OR }(95 \% \mathrm{Cl})\end{array}$ & $\begin{array}{l}\text { Cervical cancer screening } \\
\text { OR }(95 \% \mathrm{Cl})\end{array}$ & $\begin{array}{l}\text { CRC Screening } \\
\text { OR }(95 \% \mathrm{Cl})\end{array}$ \\
\hline Low health literacy & $0.41(0.20 \text { to } 0.82)^{\star}$ & $0.46(0.21$ to 1.02$)$ & 0.70 (0.38 to 1.30$)$ \\
\hline Limited English proficiency & $0.49(0.20$ to 1.22$)$ & 0.78 (0.28 to 2.22$)$ & 0.66 (0.35 to 1.22$)$ \\
\hline \multicolumn{4}{|l|}{ Education } \\
\hline Less than HS & $1.37(0.33$ to 5.61$)$ & $1.01(0.26$ to 3.98$)$ & $0.51(0.14$ to 1.88$)$ \\
\hline High school graduation & 1.19 (0.39 to 3.59$)$ & $1.30(0.40$ to 4.17$)$ & $1.02(0.46$ to 2.27$)$ \\
\hline College graduation & 0.50 (0.17 to 1.52$)$ & 1.13 (0.40 to 3.22$)$ & $0.79(0.34$ to 1.81$)$ \\
\hline More than college degree & Ref & Ref & Ref \\
\hline \multicolumn{4}{|l|}{ Control variables } \\
\hline Born in USA & 0.64 (0.13 to 3.02$)$ & $0.96(0.32$ to 2.88$)$ & 0.88 (0.42 to 1.84$)$ \\
\hline Age & 1.01 (0.96 to 1.07$)$ & $1.07(1.03 \text { to } 1.10)^{*}$ & $1.04(1.00$ to 1.08$)$ \\
\hline Female & - & - & 0.88 (0.49 to 1.57$)$ \\
\hline$\leq 100 \%$ Fed poverty level & 1.44 (0.44 to 4.71$)$ & 0.93 (0.29 to 3.04$)$ & 1.00 (0.36 to 2.79$)$ \\
\hline Rural residency & $1.25(0.19$ to 8.19$)$ & $0.42(0.08$ to 2.20$)$ & $1.21(0.22$ to 6.58$)$ \\
\hline Married & 0.61 (0.20 to 1.86$)$ & $2.37(1.13 \text { to } 5.00)^{\star}$ & 0.74 (0.26 to 2.12$)$ \\
\hline Insured & $1.02(0.26$ to 3.97$)$ & 1.27 (0.42 to 3.80$)$ & 2.27 (0.82 to 6.31$)$ \\
\hline Visited doctor in past year & $4.68(1.57 \text { to } 13.98)^{\star}$ & $2.62(1.35 \text { to } 5.11)^{*}$ & $2.10(1.07 \text { to } 4.11)^{\star}$ \\
\hline Language discordant provider & $0.55(0.20$ to 1.54$)$ & - & - \\
\hline
\end{tabular}




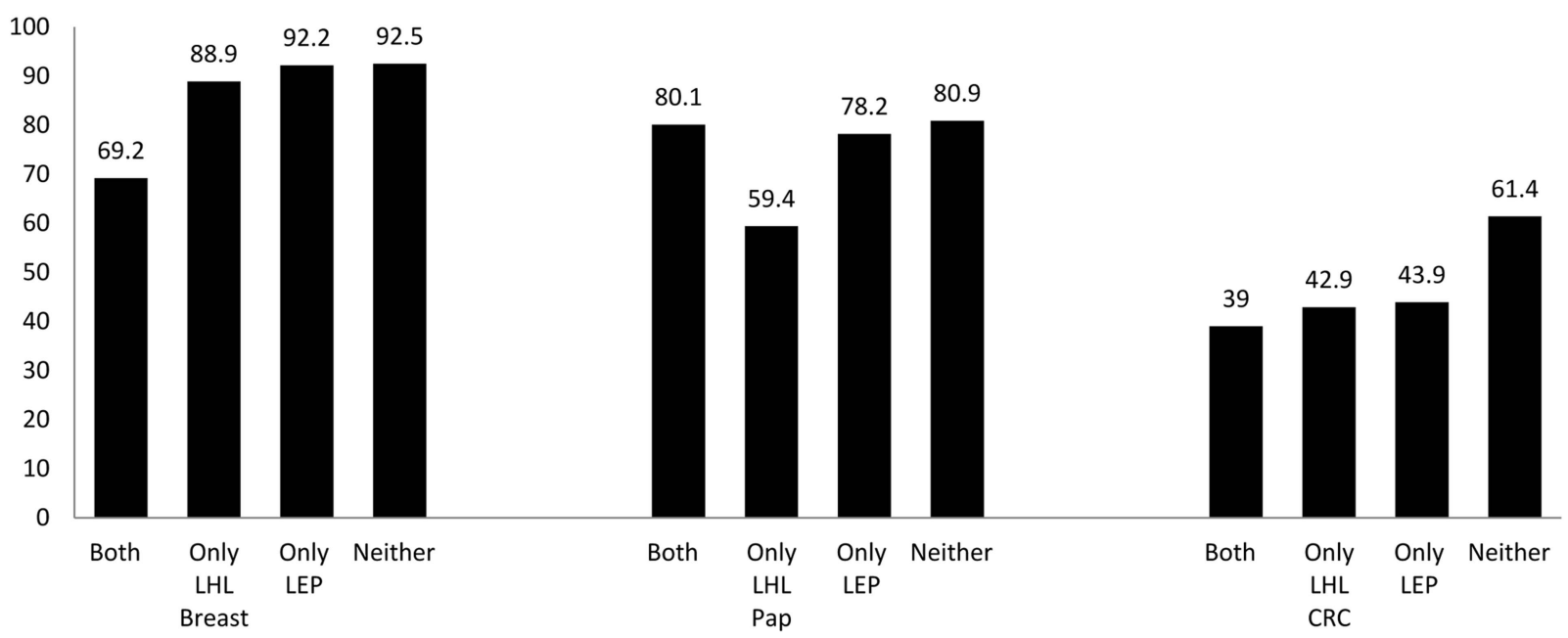

Figure 1 Per cent that met Cancer Screening Guidelines by low health literacy (LHL) and Limited English Proficiency (LEP) among Chinese respondents the 2007 CHIS. Unweighted sample sizes for the LEP/LHL combos by screening type. Breast: LHL+LEP: 75; LHL only: 32; LEP only: 40; Neither: 179; Pap: LHL+LEP: 101; LHL only: 79; LEP only: 61; Neither: 391; CRC: LHL+LEP: 103; LHL only: 61; LEP only: 52; Neither: 272.

low health literacy was significantly $(\mathrm{p}<0.05)$ associated with lower odds of meeting breast cancer screening guidelines (OR $0.41 ; 95 \%$ CI 0.20 to 0.82 ), was marginally associated with meeting cervical cancer screening guidelines (OR $0.46 ; 95 \%$ CI 0.21 to $1.02 ; \mathrm{p}=0.55$ ), and was not significantly associated with meeting colorectal cancer screening guidelines (OR $0.70 ; 95 \%$ CI 0.38 to $1.30)$. No other variables were significantly associated with mammography or CRC screening in the multivariable models. Age (older) and marital status (married) predicted screening in the cervical cancer sample.

Data on compliance with screening guidelines by the four low health literacy-LEP combination groups are shown graphically in figure 1. For breast cancer, 69.2\% of those with both LEP and low health literacy met screening guidelines, while the other three groups had over $88 \%$ screening rates (figure 1). For CRC screening, only $39 \%$ of those with both LEP and low health literacy met screening guidelines, compared to $61 \%$ of those with neither LEP nor low health literacy. However, for cervical cancer screening, the LEP and low health literacy group was not the group with the lowest per cent reaching screening guidelines. Instead, the group with lowest per cent reaching screening guidelines was those with low health literacy only.

Findings from the multivariable logistic models considering the four low health literacy-LEP combination groups (adjusted for control variables) for each screening type are provided in table 3 . In adjusted models, following the patterns in figure 1, those with both LEP and low health literacy were significantly less likely to meet breast cancer screening guidelines (OR $0.21 ; 95 \%$ CI 0.08 to 0.54 ) and colorectal cancer screening (OR 0.49; $95 \%$ CI 0.25 to 0.97 ) than those with neither LEP nor low health literacy (table 3). Visiting a doctor in the past year was again highly predictive of screening in all three models.
Considering language concordance, in descriptive analyses among those with LEP (not shown in table), not having a language concordance provider was significantly associated with poorer screening for mammography specifically $(61 \%$ with no concordant provider vs $86 \%$ with a concordant provider, $\mathrm{p}=0.01$ ). Thus, language concordance was included in the multivariable models for mammography. However, this factor was not significant in multivariable models. Language concordance was not associated with Pap or CRC screening in descriptive analyses and was not included in multivariable models for those outcomes.

\section{DISCUSSION}

Our study shows that health literacy is an important factor to consider for understanding low cancer screening rates among Chinese Americans. Low health literacy alone was associated with lower odds of meeting breast cancer screening guidelines and those with both LEP and low health literacy appear to be at particularly high risk for not meeting colorectal and breast cancer screening guidelines. Even after considering having a recent visit with a physician, having low health literacy and limited English proficiency together was an independent predictor of screening for two out of three cancer screening types. Visiting a doctor in the past year was also highly predictive of all three types of cancer screening. This highlights the importance of healthcare system access above and beyond insurance coverage in ensuring receipt of needed preventive care. We also note that English proficiency and health literacy appear to have distinct relationships with the three types of cancer screening.

Our findings suggest that for breast cancer interventions in particular, strategies to improve health literacy (such as simplifying health information) or to increase 
Table 3 Logistic models predicting met the US preventive service task force cancer screening guidelines for breast, cervical and colorectal cancer (CRC) by low health literacy (LHL) and limited English proficiency (LEP) combinations in 2007 California Health Interview Survey among Chinese respondents

\begin{tabular}{|c|c|c|c|}
\hline & $\begin{array}{l}\text { Breast cancer screening } \\
\text { OR }(95 \% \mathrm{Cl})\end{array}$ & $\begin{array}{l}\text { Cervical cancer screening } \\
\text { OR }(95 \% \mathrm{Cl})\end{array}$ & $\begin{array}{l}\text { CRC screening } \\
\text { OR }(95 \% \mathrm{Cl})\end{array}$ \\
\hline \multicolumn{4}{|l|}{ LHL and LEP combinations } \\
\hline LHL and LEP & $0.21(0.08 \text { to } 0.54)^{*}$ & $0.41(0.15$ to 1.13$)$ & $0.49(0.25 \text { to } 0.97)^{*}$ \\
\hline LEP only & 0.85 (0.27 to 2.72$)$ & $0.60(0.15$ to 2.34$)$ & $0.50(0.21$ to 1.17$)$ \\
\hline LHL only & 0.92 (0.24 to 3.57$)$ & $0.37(0.15 \text { to } 0.92)^{*}$ & $0.50(0.23$ to 1.08$)$ \\
\hline Neither & Ref & Ref & Ref \\
\hline \multicolumn{4}{|l|}{ Education } \\
\hline Less than HS & $1.34(0.32$ to 5.73$)$ & $0.92(0.23$ to 3.73$)$ & $0.50(0.14$ to 1.82$)$ \\
\hline High school graduation & $1.10(0.34$ to 3.45$)$ & $1.28(0.40$ to 4.10$)$ & 1.01 (0.46 to 2.26$)$ \\
\hline College graduation & $0.46(0.16$ to 1.37$)$ & $1.14(0.40$ to 3.28$)$ & 0.77 (0.33 to 1.77$)$ \\
\hline More than college degree & Ref & Ref & Ref \\
\hline \multicolumn{4}{|l|}{ Control variables } \\
\hline Born in USA & $0.72(0.16$ to 3.26$)$ & $0.91(0.30$ to 2.75$)$ & $0.85(0.41$ to 1.80$)$ \\
\hline Age & $1.02(0.96$ to 1.07$)$ & $1.06(1.03 \text { to } 1.10)^{*}$ & 1.04 (0.99 to 1.08$)$ \\
\hline Female & - & - & $0.89(0.49$ to 1.61$)$ \\
\hline$\leq 100 \%$ Fed poverty level & $1.50(0.44$ to 5.13$)$ & $0.95(0.29$ to 3.08$)$ & 0.96 (0.35 to 2.64$)$ \\
\hline Rural residency & $1.01(0.17$ to 6.06$)$ & 0.45 (0.09 to 2.20$)$ & $1.23(0.25$ to 6.07$)$ \\
\hline Married & $0.66(0.23$ to 1.89$)$ & $2.29(1.06 \text { to } 4.94)^{*}$ & $0.76(0.27$ to 2.10$)$ \\
\hline Insured & $0.92(0.23$ to 3.66$)$ & $1.31(0.44$ to 3.91$)$ & $2.32(0.81$ to 6.64$)$ \\
\hline Visited doctor in past year & $4.90(1.67 \text { to } 14.36)^{\star}$ & $2.57(1.31 \text { to } 5.05)^{*}$ & $2.04(1.06 \text { to } 3.93)^{*}$ \\
\hline Language discordant provider & $0.59(0.21$ to 1.63$)$ & - & - \\
\hline
\end{tabular}

${ }^{*}$ Factors significant $\mathrm{p}<0.05$.

LEP, limited English proficiency; LHL, lowhealth literacy; HS, high school.

the health-literate nature of the healthcare organisation (such as confirming understanding at all points of patient contact) ${ }^{48} 49$ may increase screening in Chinese Americans, particularly in concert with other proven strategies. ${ }^{50}{ }^{51}$ It also suggests that including health literacy in multivariable studies of factors associated with Chinese American cancer screening may be important to understand all significant contributors to screening behaviour in this group.

We also find that Chinese Americans with the combined barriers of LEP and limited health literacy are a particularly vulnerable population for colorectal and breast cancer screening. This supports previously findings of linguistic barriers to care and low cancer screening rates among Chinese Americans with $\mathrm{LEP}^{52-54}$ with further insight about the additional burden of low health literacy. Of relevance, in a previous study of LEP and low health literacy with CHIS data, Chinese reported the highest rates of both low health literacy and LEP compared to other racial/ethnic groups. ${ }^{38}$

Those with both LEP and low health literacy may fall outside many existing pathways of health communication as both English or adapted Chinese language print materials may not be accessible. Promising research has found that multifaceted, culturally and linguistically appropriate interventions, including health educators in the primary care setting, can improve cancer screening in Chinese American populations. ${ }^{55} 56$ Such interventions may be critically important for those with LEP and low health literacy in order to illuminate screening access opportunities and to combat misconceptions about screening (such as whether women who are not sexually active should be screened). ${ }^{55} 56$

Our findings also reveal the critical importance of regular access to a physician. Previous studies have shown that this access factor is associated with higher rates of preventive care and early detection of disease, but that regular visits to a doctor are less common among minority racial/ethnic groups, especially those with LEP. ${ }^{57} 58$ The powerful role of this variable in our study reveals the particular importance of this factor for Chinese Americans in general, and as a way to potentially overcome the impacts of health communication barriers of LEP and low health literacy specifically. This finding has critical current policy relevance in light of the expanded insurance coverage under the Affordable Care Act. Our study emphasises that insurance alone is only the first step to receiving needed preventing care; an actual connection with the healthcare system is also critical.

Our research found distinct relationships for low health literacy and LEP by screening type. This may be related to differential health literacy and health communication demands by screening type. The three cancer screening types vary in procedural complexity, direct patient involvement, and/or the number of contact or communication points needed to complete the screening. For cervical cancer screening with a Pap test, the procedure is often completed in a single medical visit with minimal preparation by the patient. Our results 
showed that visiting a doctor in the past year was particularly critical for receiving this procedure specifically and neither of our health communication variables was significant in the cervical cancer models when this factor was included. For mammography, the complexity of screening completion is higher, as it can require navigating (and potentially scheduling) a separate visit often at a different location than the doctor's office. Our findings showed that low health literacy has an independent association with low mammography screening and that the combined burdens from both low health literacy and LEP exacerbate the barriers for obtaining mammography. CRC screening is the most complex of our tested screening procedures, involving multiple contact points and including previsit preparations (such as stool collection and handling for Fecal Occult Blood Test or Fecal Immunochemical Test or dietary preparations prior to colonoscopy). These screening procedures demand literacy skills to comprehend and implement instructions. Among Chinese Americans, CRC screening had the lowest adherence rate among the three cancers studied, and the combined burdens of low health literacy and LEP were associated with lower rates of up-to-date CRC screening in this population.

Both culturally and linguistically appropriate services are likely needed to reduce healthcare disparities. ${ }^{59}$ While having a recent doctor visit was highly predictive of receipt of cancer screening, health communication variables were also important. Healthcare systems and providers able to effectively address Chinese specific cultural concerns around cancer screening are needed, ${ }^{55} 56$ especially for those with limited understanding of the US medical system (for which LEP and/or low health literacy may be proxy measures).

This study has many strengths, such as a populationbased data set with significant numbers of Chinese Americans, including those with LEP. However, some issues should be considered during interpretation. The health literacy items have been used in a number of previous studies ${ }^{19} \quad 37 \quad 38$ and were taken from the Commonwealth Fund's 2006 Quality of Care Survey, ${ }^{60}$ but they are self-reported and only focus on some aspects of health literacy. Also, to our knowledge, such self-reported health literacy items have been validated in English speakers ${ }^{39}$ and studied in Asian groups outside the USA, ${ }^{61}$ but have not been validated in Chinese Americans specifically. It would be useful to consider differences in self-reporting health literacy challenges across Asian groups in the USA, due to known cultural differences in responses to questionnaires, including gender differences. ${ }^{61}$ It would also be useful to see how other health literacy domains, such as the ability not just to understand, but also to communicate, are described by Chinese Americans and how these might be impacted by LEP. Our CHIS data lack some variables, including cultural and health belief-related factors, associated with cancer screening in Chinese Americans. ${ }^{62} 63$ We also lacked the sample size to consider the independent role of factors that are highly associated with our included study variables (especially LEP and birthplace), but likely have distinct roles with cancer screening (such as Chinese language of preference, time in the USA, and other acculturation variables). Future study should consider the role of health literacy along with these variables.

Cancer screening among Chinese Americans also varies by geographic location. For instance, in Hawaii, Chinese Americans have higher cancer screening compliance than many other racial/ethnic groups, and higher rates of screening than are seen in these data from California. ${ }^{64}$ It would be helpful to see if the role of health literacy and/or LEP also varies, or if other factors are at play. These areas also have distinct patterns of immigration and differential percentages of Chinese relative to the larger population that may also be important in explaining these findings. ${ }^{2}$

\section{CONCLUSIONS}

This study provides important new information about the role of low health literacy and limited English proficiency in cancer screening guideline adherence among Chinese Americans. Health literacy is increasingly recognised as an important factor in healthcare access and cancer screening in particular and is distinct from, but associated with, limited English proficiency. Efforts to promote screening in Chinese American communities should consider the health communication barriers of low health literacy and LEP separately and in combination to improve screening rates in these populations. Physician access barriers should also be considered as these appear critically important to cancer screening among Chinese Americans.

Contributors TLS conceived and designed the study, obtained the funding and drafted the manuscript. JYT helped to draft the manuscript, interpret analyses and contextualise study findings. TD participated in the study design and coordination and helped to draft the manuscript. JD participated in the design of the study, performed the statistical analysis and helped to draft the manuscript. KLB participated in the study design and coordination, and helped to draft the manuscript. All authors read and approved the final manuscript.

Funding This work was supported by the National Cancer Institute (1R03CA158419). Support for KLB was also provided by U54CA153459 from the National Cancer Institute. Support for JYT was supported by R01 CA138778 from the National Cancer Institute. Support for JD was also provided by U54MD007584 and G12MD007601 from the National Institute on Minority Health and Health Disparities. Support for TD was also provided by 1 U54 GM104940 from the National Institute of General Medical Sciences of the National Institutes of Health, which funds the Louisiana Clinical and Translational Science Center.

Competing interests None.

Ethics approval This study was deemed exempt by the University of Hawaii IRB.

Provenance and peer review Not commissioned; externally peer reviewed.

Data sharing statement The $2007 \mathrm{CHIS}$ public use data files used in this study can be downloaded at no cost from http://healthpolicy.ucla.edu/chis/data/ Pages/overview.aspx. For any additional questions about specific study analyses and data (eg, variable specification), please email tsentell@hawaii.edu. 
Open Access This is an Open Access article distributed in accordance with the Creative Commons Attribution Non Commercial (CC BY-NC 4.0) license, which permits others to distribute, remix, adapt, build upon this work noncommercially, and license their derivative works on different terms, provided the original work is properly cited and the use is non-commercial. See: http:// creativecommons.org/licenses/by-nc/4.0/

\section{REFERENCES}

1. Centers for Disease Control. 10 leading causes of death; Asian American and Pacific Islander population, US, 2006. Leading causes of death by race/ethnicity 2010 (cited 4 March 2014). http://www.cdc. gov/minorityhealth/populations/REMP/asian.html

2. United States Census Bureau. The Asian population: 2010 United States Census Bureau. US Census Briefs, 2012 (cited 15 February 2014). https://www.census.gov/prod/cen2010/briefs/c2010br-11.pdf

3. Kagawa-Singer M, Pourat N. Asian American and Pacific Islander breast and cervical carcinoma screening rates and Healthy eople 2000 Objectives. Cancer 2000;89:696-705.

4. Chen JY, Diamant AL, Kagawa-Singer M, et al. Disaggregating data on Asian and Pacific Islander women to assess cancer screening. Am J Prev Med 2004;27:139-45.

5. Tang TS, Solomon LJ, McCracken LM. Barriers to fecal occult blood testing and sigmoidoscopy among older Chinese-American women. Cancer Pract 2001;9:277-82.

6. Gomez SL, Noone AM, Lichtensztajn DY, et al. Cancer incidence trends among Asian American populations in the United States, 1990-2008. J Natl Cancer Inst 2013;105:1096-110.

7. Yu ES, Kim KK, Chen EH, et al. Breast and cervical cancer screening among Chinese American women. Cancer Pract 2001;9:81-91.

8. US Department of Health and Human Services. HP 2010. 2nd edn. With understanding and improving health and objectives for improving health. 2 vols. Washington DC: US Government Printing Office, 2000.

9. Scott TL, Gazmararian JA, Williams MV, et al. Health literacy and preventive health care use among Medicare enrollees in a managed care organization. Med Care 2002;40:395-404

10. Davis TC, Williams MV, Marin E, et al. Health literacy and cancer communication. CA Cancer J Clin 2002;52:134.

11. Bennett CL, Ferreira MR, Davis TC, et al. Relation between literacy, race, and state of presentation among low-income patients with prostate cancer. J Clin Oncol 1998;16:3101-4.

12. Peterson NB, Dwyer KA, Mulvaney SA, et al. The influence of health literacy on colorectal cancer screening knowledge, beliefs, and behaviors. J Natl Med Assoc 2007;99:1105-12.

13. Davis TC, Dolan NC, Ferreira MR, et al. The role of inadequate health literacy skills in colorectal cancer screening. Cancer Invest 2001;19:193-200.

14. Dolan NC, Ferreira MR, Davis TC, et al. Colorectal cancer screening knowledge, attitudes, and beliefs among veterans: does literacy make a difference? J Clin Oncol 2004;22:2617-22.

15. Miller DP, Brownlee CD, McCoy TP, et al. The effect of health literacy on knowledge and receipt of colorectal cancer screening: a survey study. BMC Fam Pract 2007;8:16.

16. Guerra CE, Dominguez F, Shea JA. Literacy and knowledge, attitudes, and behavior around colorectal cancer screening. $J$ Health Commun 2005;10:651-63.

17. Lindau ST, Tomori $\mathrm{C}$, Lyons $\mathrm{T}$, et al. The association of health literacy with cervical cancer prevention knowledge and health behaviors in a multiethnic cohort of women. Am J Obstet Gynecol 2002;186:938-43.

18. Lindau ST, Anirban B, Leitsch SA. Health literacy as predictor of follow-up after an abnormal Pap smear: a prospective study. J Gen Intern Med 2006;21:829-34.

19. Sentell T, Braun KL, Davis J, et al. Colorectal cancer screening: low health literacy and limited English proficiency among Asians and Whites in California. J Health Commun 2013;18:242-55.

20. US Census Bureau. Language use and English speaking ability: 2000. Washington DC: US Department of Commerce, 2003.

21. Jacobs EA, Karavolos K, Rathouz PJ, et al. Limited English proficiency and breast and cervical cancer screening in a multiethnic population. Am J Public Health 2005;95:1410-16.

22. Ma GX, Gao W, Lee S, et al. Health seeking behavioral analysis associated with breast cancer screening among Asian American women. Int J Womens Health 2012;4:235-43.

23. Association of Asian Pacific Community Health Organizations. AAP Limited English Proficiency (LEP). Association of Asian Pacific Community Health Organizations (AAPCHO) fact sheet. 2005 (cited
15 February 2014). http://www.aapcho.org/wp/wp-content/uploads/ 2012/02/AAPCHO FactSheet-AAPI LEP 2005.pd

24. US Preventive Services Task Force. Screening for breast cancer recommendations. 2009 (cited 8 November 2013). http://www. uspreventiveservicestaskforce.org/uspstf/uspsbrca.htm

25. US Preventive Services Task Force. Screening for cervical cancer. 2012 (cited 8 November 2013). http://www.uspreventiveservices taskforce.org/uspstf11/cervcancer/cervcancerrs.htm\#summary

26. US Preventive Services Task Force. Screening for colorectal cancer. 2008 (cited 8 November 2013). http://www. uspreventiveservicestaskforce.org/uspstf/uspscolo.htm

27. California Health Interview Survey. About the California Health Interview Survey. UCLA Center for Health Policy Research. (cited 8 November 2013). http://healthpolicy.ucla.edu/chis/Pages/default. aspx

28. US Census Bureau. The Asian population: 2000. Census 2000 brief. (cited 15 February 2014). http://www.census.gov/prod2002pubs/ c2kbr01-16.pdf

29. California Health Interview Survey (CHIS). CHIS 2007 methodology series: report 2-data collection methods. Los Angeles, CA: UCLA Center for Health Policy Research, 2009 (cited 24 September 2014). http://healthpolicy.ucla.edu/chis/design/Documents/CHIS2007_ method2.pdf

30. California Health Interview Survey (CHIS). CHIS 2007 Sample Design. UCLA Center for Health Policy Research (cited 15 February 2014). http://healthpolicy.ucla.edu/chis/design/Documents/sample desc_2007.pdf

31. Gomez SL, Tan S, Keegan TH, et al. Disparities in mammographic screening for Asian women in California: a cross-sectional analysis to identify meaningful groups for targeted intervention. BMC Cancer 2007;7:201.

32. Kagawa-Singer M, Pourat N, Breen N, et al. Breast and cervical cancer screening rates of subgroups of Asian American women in California. Med Care Res Rev 2007;64:706.

33. Wong ST, Gildengorin G, Nguyen T, et al. Disparities in colorectal cancer screening rates among Asian Americans and non-Latino whites. Cancer 2005;104(12 Suppl):2940-7.

34. Kandula NR, Wen M, Jacobs EA, et al. Low rates of colorectal, cervical, and breast cancer screening in Asian Americans compared with Non-Hispanic Whites. Cancer 2006;107:184-92.

35. Breslau ES, Jeffery DD, Davis WW, et al. Cancer screening practices among racially and ethnically diverse breast cancer survivors: results from the 2001 and 2003 California health interview survey. J Cancer Surviv 2010;4:1-14.

36. Hiatt RA, Klabunde $\mathrm{C}$, Breen $\mathrm{N}$, et al. Cancer screening practices from National Health Interview Surveys: past, present, and future. J Natl Cancer Inst 2002;94:1837-46.

37. Health Research for Action. Investigating the intersection between health literacy and health plan efficiency. Berkeley: University of California, 2009. Submitted to the Office of the Patient Advocate (cited 15 February 2014). http://www.opa.ca.gov/Documents/ Reports/executive-summary-health-care-access\%28HRA\%29.pdf

38. Sentell T, Braun KL. Low health literacy, limited English proficiency, and health status across Latino and Asian Americans in California. $J$ Health Commun 2012;17:82-99.

39. Chew LD, Griffin JM, Partin MR, et al. Validation of screening questions for limited health literacy in a large VA outpatient population. J Gen Intern Med 2008;23:561-6.

40. Flores G, Abreu M, Tomany-Korman SC. Limited English proficiency, primary language at home, and disparities in children's health care: how language barriers are measured matters. Public Health Rep 2005;120:418-30.

41. Cordasco KM, Ponce NA, Gatchell MS, et al. English language proficiency and geographical proximity to a safety net clinic as a predictor of health care access. J Immigr Minor Health 2011;13:260-7.

42. Ponce NA, Hays RD, Cunningham WE. Linguistic disparities in health care access and health status among older adults. J Gen Intern Med 2006;21:786-91.

43. Berkman ND, Sheridan SL, Donahue KE, et al. Low health literacy and health outcomes: an updated systematic review. Ann Intern Med 2011;155:97-107.

44. Eamranond PP, Davis RB, Phillips RS, et al. Patient-physician language concordance and primary care screening among Spanish-speaking patients. Med Care 2011;49:668-72.

45. August $\mathrm{KJ}$, Nguyen $\mathrm{H}$, Ngo-Metzger $\mathrm{Q}$, et al. Language concordance and patient-physician communication regarding menta health needs. J Am Geriatr Soc 2011;59:2356-62.

46. StataCorp. Stata Statistical Software: Release 12. College Station, TX: StataCorp LP, 2011.

47. California Health Interview Survey (CHIS). CHIS 2007 methodology series: report 5-weighting and variance estimation. Los Angeles, 
CA: UCLA Center for Health Policy Research, 2009 (cited 30 September 2014). http://healthpolicy.ucla.edu/chis/design/ Documents/CHIS2007_method5.pdf

48. Brach C, Keller D, Hernandez LM, et al. Ten attributes of a health literate health care organization. Washington DC: Institute of Medicine, 2012 (cited 14 February 2014). http://iom.edu/ /media/ Files/Perspectives-Files/2012/Discussion-Papers/BPH_Ten_HLit_ Attributes.pdf

49. Sheridan SL, Halpern DJ, Viera AJ, et al. Interventions for individuals with low health literacy: a systematic review. J Health Commun 2011;16:30-54.

50. Lu M, Moritz S, Lorenzetti D, et al. A systematic review of interventions to increase breast and cervical cancer screening uptake among Asian women. BMC Public Health 2012;12:413.

51. Hou SI, Sealy DA, Kabiru CW. Closing the disparity gap: cance screening interventions among Asians-a systematic literature review. Asian Pac J Cancer Prev 2011;12:3133-9.

52. Ponce N, Gatchell M, Brown RE. Cancer screening rates among Asian ethnic groups. 2003 (cited 15 February 2014). http://healthpolicy.ucla. edu/publications/Documents/PDF/Cancer\%20Screening\%20Rates\% 20Among\%20Asian\%20Ethnic\%20Groups.pdf

53. Ngo-Metzger Q, Massagli MP, Clarridge BR, et al. Linguistic and cultural barriers to care. J Gen Intern Med 2003;18:44-52.

54. Todd L, Hoffman-Goetz L. A qualitative study of cancer information seeking among English-as-a-second-Language older Chinese immigrant women to Canada: sources, barriers, and strategies. $J$ Cancer Educ 2011;26:333-40.

55. Taylor VM, Jackson JC, Tu SP, et al. Cervical cancer screening among Chinese Americans. Cancer Detect Prev 2002;26:139-45.

56. Tu SP, Taylor V, Yasui Y, et al. Promoting culturally appropriate colorectal cancer screening through a health educator: a randomized controlled trial. Cancer 2006;107:959-66.
57. Center for Studying Health Systems Change. Access to Care. Results from the Community Tracking Study, No 2. June 2002. (cited 30 September 2014). http://hschange.com/CONTENT/443/ 443.pdf

58. Ku L, Waidmann T. How Race/Ethnicity, Immigration Status and Language Affect Health Insurance Coverage, Access to Care and Quality of Care Among the Low-Income Population, prepared for the Kaiser Commission on Medicaid and the Uninsured, August 2003. Publication \#4132 (cited 30 September 2014). http:// kaiserfamilyfoundation.files.wordpress.com/2013/01/how-raceethnicity-immigration-status-and-language-affect-health-insurancecoverage-access-to-and-quality-of-care-among-the-low-incomepopulation.pdf

59. Anderson LM, Scrimshaw SC, Fullilove MT, et al. Culturally competent healthcare systems. A systematic review. Am J Prev Med 2003;24:68-79.

60. The Commonwealth Fund. The Commonwealth Fund 2006 Health Care Quality Survey (cited 2 Jun 2010). http://www. commonwealthfund.org/Content/Surveys/2006/The-CommonwealthFund-2006-Health-Care-Quality-Survey.aspx

61. Lee SY, Tsai TI, Tsai YW. Accuracy in self-reported health literacy screening: a difference between men and women in Taiwan. BMJ Open 2013;3:e002928.

62. Chang SC, Woo JS, Yau V, et al. Cervical cancer screening and Chinese women: insights from focus groups. Front Psychol 2013;4:48

63. Ma GX, Wang MQ, Ma XS, et al. Pathways of cervical cancer screening among Chinese women. Int $J$ Womens Health 2013;5:351-9.

64. Hawaii Department of Health. Hawaii cancer facts and figures 2010 (cited 8 November 2013). http://health.hawaii.gov/about/files/2013/ 06/Hawaii_Cancer_Facts_and_Figures_2010.pdf 